\title{
Políticas públicas em esportes no Brasil
}

\author{
Valéria da Silva Augusto de Oliveira ${ }^{1}$
}

\section{Resumo}

O presente artigo versa sobre as políticas públicas em esportes no Brasil. Objetiva este trabalho investigar, à luz do artigo 217 da Constituição da República - que determina ser dever do Estado fomentar práticas desportivas formais e não formais como direito de cada um - e demais legislações infraconstitucionais pertinentes ao assunto, quais medidas estão sendo tomadas para a efetivação e promoção do desporto educacional, do desporto de alto rendimento e do lazer e se são efetivas, eficientes e eficazes. Para tanto, abordar-se-á sobre a política de esportes no mundo e no Brasil, traçando-se um panorama histórico e conceituando esporte e políticas públicas. Em seguida, será traçado breve histórico das ações em políticas públicas em esportes no Brasil e informar-se-á acerca da atual Política Nacional do Esporte, da qual serão coletados os dados sobre as ações propostas e os atores envolvidos, fornecendo-se um panorama de como a matéria está sendo tratada atualmente. Ao final, será possível avaliar essas ações e montar um quadro crítico da política social referente aos esportes no país.

Palavras-chaves: Política pública. Desporto. Esportes. História. Modelo. Atores. Incremento. Proposições. Avaliação. Eficiência. Eficácia. Efetividade.

\section{Introdução}

A discussão sobre políticas públicas em esportes foi escolhida por uma paixão pelos esportes, e pela curiosidade de saber como se desenvolvem os programas nessa área.

\footnotetext{
* Artigo recebido em agosto/2011 Aprovado em agosto/2011

1 Valéria da Silva Augusto de Oliveira é servidora do Tribunal Superior do Trabalho, Bacharel em Letras (Licenciatura Plena) pelo UniCeub, pós-graduada em Produção Textual pela Faculdade Albert Einstein - São Paulo - e graduanda em Direito também pelo UniCeub.
} 
Investiga-se, então, como essas políticas podem efetivamente influir na vida de pessoas carentes, ajudando-as de alguma forma melhorar a qualidade de suas vidas e a ocupar melhores espaços na sociedade.

Além disso, ouvem-se diariamente notícias desanimadoras a respeito dos escândalos de corrupção praticados por dirigentes e gestores públicos.

Procurou-se, com isso, saber mais sobre o que fazem as pessoas públicas que estão à frente dessas discussões e como agem diante de tantos desafios.

Para tanto, em primeiro plano, conceituam-se esportes e políticas públicas. Em um segundo plano, histórico, conta-se quando e como as políticas públicas surgiram no mundo e no Brasil e em que momento e sob que condições o esporte foi erigido a uma questão de Estado no nosso país. Em terceiro lugar, informa-se sobre as políticas públicas em esportes no Brasil, traçando um histórico das ações implementadas desde a Era Vargas até os nossos dias. Por último, avalia-se se essas ações desenvolvidas são efetivas, eficientes e eficazes, de acordo com a forma como foram implementadas e os resultados atingidos.

\section{Conceito de esporte}

Segundo Manoel José Gomes Tubino, ${ }^{2}$ o esporte moderno, bem assim a forma organizada como ele hoje se configura, é decorrente dos "impactos da evolução social britânica do século XVIII e da estruturação pedagógico-esportiva da Inglaterra do século XIX”. Conta também Tubino que a evolução do conceito de esporte teve início com Thomas Arnold, que, em 1928, dividiu o esporte naquilo que chamou de "elementos" ou "características", a saber: o jogo, a competição e a formação.

Coubertin, criador do Comitê Olímpico Internacional (COI), foi incumbido de desenvolver o esporte olímpico como movimento filosófico. Para ele, segundo

2 CAGigal, J. M. apud TUBINO, Manoel Gomes. Teoria geral do esporte. São Paulo: IBRASA, 1987. p.23. 
Gillet, ${ }^{3}$ o esporte era considerado “[...] o culto voluntário e habitual do esforço muscular intensivo apoiado sobre o desejo de progresso e podendo chegar até o risco”.

Descreve Tubino que há os que vinculam o esporte ao conceito de jogo, como sendo a forma socializada da competição. Para esses, o esporte não só é exercício físico, de caráter competitivo, mas também cumpre função higiênica, educativa, hedonística, biológica, de promoção social, constituindo-se em uma "conduta lúdica de alcance psicossomático".

Por outro lado, Bouet ${ }^{4}$ afirma que “O esporte é efetivação, aplicação de princípios, normas, superação, consciência do indivíduo, busca objetivos, especialização".

Antoneli, ${ }^{5}$ por sua vez, afirma, ao conceituar o esporte, que ele possui três elementos básicos (o jogo, o movimento e o agonismo), este último significando competição, e quatro características: ético-social, psicopedagógica, psicoprofilática e psicoterapêutica.

Porém, para Tubino, o grande marco no conceito de esporte foi o Manifesto do Esporte, promovido pelo Conseil Internationale d'Education Physique et Sport, organismo ligado à UNESCO, que tratou o esporte na perspectiva do tempo livre e da escola, além de fazer referência ao esporte de competição. Além desse manifesto, a Carta Europeia de Esporte para Todos, de 1966, considerou o esporte como fenômeno de participação.

Após passar por inúmeros pensadores, diferentes conceituações e interpretações e também pelo Manifesto do Esporte - que logrou êxito em ampliar o conceito de esporte, validado pela Carta Europeia de Esporte para Todos -, o esporte, segundo Tubino 6 , passa a ser considerado "[...] todas as formas de movimento

3 GILLET, B. apud TUBINO, Manoel Gomes. Teoria geral do esporte. São Paulo: IBRASA, 1987. p.25.

4 BOUET, M. apud TUBINO, Manoel Gomes. Teoria geral do esporte. São Paulo: IBRASA, 1987, p. 26.

5 ANTONELI apud TUBINO, Manoel Gomes. Teoria geral do esporte. São Paulo: IBRASA, 1987, p. 27.

6 TUBINO, Manoel Gomes. Teoria geral do esporte. São Paulo: IBRASA, 1987. p. 33. 
físico que se vinculam à recreação e condição física, como as corridas e outras atividades casuais, localizando-as nas manifestações do chamado esporte popular”.

O estrito sentido dado ao esporte, visto antes como atividades humanas de número limitado, realizadas sob o caráter competitivo, foi ampliado e todas as formas de movimento físico possíveis, hoje, podem ser interpretadas como atividades esportivas.

Até os processos de aprendizagem esportiva tiveram que ser revistos, tendo em vista que terão que ser compreendidos na estrutura social em que estiverem inseridos. Ficou claro, dessa forma, que as estruturas sociais nas quais estiverem situadas as pessoas serão preponderantes para o comportamento esportivo, e a cultura será determinante nessa participação.

O esporte, assim, é elemento constituinte do bem-estar, muito mais do que atividade de utilidade econômica. A participação passa a ter papel predominante e constitui-se em uma nova característica do esporte contemporâneo. Já o esporte de competição, de alto rendimento, passa a tornar-se mais um trabalho do que propriamente um jogo.

Para Deccache-Maia ${ }^{7}$, o esporte, atualmente, tamanha se configurou sua importância, que é utilizado como "atividade alvo de ações políticas revestidas de cunho social”, já que faz parte da formação do indivíduo.

\section{Conceito de políticas públicas ${ }^{8}$}

Assim como o conceito de esporte, também o conceito de políticas públicas sofreu uma evolução, advinda da evolução da própria sociedade.

7 DECCACHE-MAIA, Eline. Esporte e políticas públicas no Brasil. Disponível em: <www. lazer.eefd.ufrj.br/spsoc.

8 RODRIGUES, Marta Assumpção. Políticas públicas. São Paulo: Publifolha, 2010. 
Aristóteles, em sua obra "A Política", em que reflete sobre o Estado e suas formas de governo, definiu o termo "política" como "a ciência da felicidade humana”. Acreditava esse pensador que a política deveria estar ligada ao bem-estar humano e que qualquer forma de governo deveria ser capaz de assegurar esse benefício aos seus governados.

Gradativamente, o termo "política” foi se transformando e passou a significar o conjunto de atividades que, de alguma forma, estivessem relacionadas ao Estado. Infere-se, pois, que o ser humano deixou de ser a prioridade, que passou a ser o próprio Estado, e este se utiliza do poder de coerção e do uso da força, se necessário, para fazer valer seus interesses.

Ao se pensar, também, na significação do termo "Estado", verifica-se que houve uma transformação no conceito, partindo do Estado como forma de realização humana - considerada por Aristóteles e Platão - para a ideia de que tal instituição era um mal ou um castigo infringido ao indivíduo, até a era moderna, em que o Estado é considerado um promotor da saúde, da educação e do desenvolvimento, havendo uma preocupação com o que esse Estado faz, na prática, para o bem-estar do povo que o compõe, ou seja, com o modo de se governar.

Dessa forma, os indivíduos que compõem o Estado são aqueles que orientam, por meio de um processo decisório, em última instância, os rumos do próprio Estado, tendo o poder de escolher que práticas serão aplicadas para a promoção do bem-estar de todos, vale dizer, que política será adotada para a resolução de seus conflitos. Forma-se, assim, o Governo, que decide por meio de políticas e com fundamento nas leis que elabora.

Segundo entendimento de Marta Assumpção Rodrigues?., "políticas públicas são resultantes da atividade política, requerem várias ações estratégicas destinadas a implementar os objetivos desejados e, por isso, envolvem mais de uma decisão política”.

\footnotetext{
9 RODRIGUES, Marta Assumpção. Políticas públicas. São Paulo: Publifolha, 2010. p.14.
} 
As ações e decisões de que são constituídas as políticas públicas revestem-se da autoridade soberana do poder público. As pessoas com poder de produzir políticas públicas são os "atores", que detêm poder para tomar decisões públicas, incidentes sobre todos os sujeitos que, de uma forma ou de outra, vão-se beneficiar daquelas políticas.

Assim, existem os atores que decidem - gestores públicos, juízes, parlamentares, burocratas, membros do executivo, organizações públicas e instituições privadas - e os que se beneficiam, ou sofrem a ação, os sujeitos passivos daquelas decisões.

Ao se refletir sobre o conceito de políticas públicas, verifica-se que não há um consenso a respeito de uma definição única e precisa do termo. Maria Helena Castro $^{10}$ apresenta diferentes concepções. De modo geral, as duas definições trazidas por ela são a do "Estado em ação"- implicando que todo tipo de ação direcionada ao bem comum da sociedade provém do Estado - e a da política social, que coloca como política pública todo tipo de iniciativa destinada a beneficiar a coletividade, não especificando a necessidade da participação do Estado.

Para Enrique Saraiva ${ }^{11}$, uma política pública é toda ação (ou, curiosamente, omissão) destinada a, por meio de prevenção ou correção, manter uma realidade social considerada boa ou modificar uma situação social que esteja em desacordo com o desejável. Ele especifica o processo de construção das políticas públicas, descrevendo diferentes fases: observação e avaliação do panorama, estudo de necessidades, elaboração de plano, implementação, acompanhamento de efetividade, avaliação de resultados etc.

\footnotetext{
${ }^{10}$ CASTRO, Maria Helena Guimarães. Políticas Públicas: conceitos e conexões com a realidade brasileira. In: CANELA, Guilherme (Org.). Políticas públicas sociais e os desafios para o jornalismo. São Paulo: Cortez, 2008. p. 66-89.

11 SARAIVA, Enrique. Introdução à teoria da política pública. In: SARAIVA, Enrique; FERNANDES, Elisabete. (Org.). Políticas públicas. Brasília: ENAP, 2007. Coletânea, v. 1. p. 21-43.
} 
Eduardo Appio ${ }^{12}$, por sua vez, define políticas públicas como "instrumentos de execução de programas políticos”, que seriam baseados na intervenção do Estado na sociedade visando garantir igualdade de oportunidades aos cidadãos. Para Appio, as políticas públicas denotam a vontade do Estado em criar um planejamento social a partir da execução de "projetos governamentais das sociedades contemporâneas".

Em conclusão, é possível afirmar que, embora não haja um conceito único para políticas públicas, elas se constatam nas ações governamentais necessárias a produzir respostas às necessidades da sociedade.

\section{Políticas públicas no mundo}

De acordo com Fábio Guedes Gomes ${ }^{13}$, Estado de Bem-estar Social (ou Welfare Satate) pode ser definido como:

[...] um conjunto de serviços e benefícios sociais de alcance universal promovidos pelo Estado com a finalidade de garantir uma certa 'harmonia' entre o avanço das forças de mercado e uma relativa estabilidade social, suprindo a sociedade de benefícios sociais que significam segurança aos indivíduos para manterem um mínimo de base material e níveis de padrão de vida, que possam enfrentar os efeitos deletérios de uma estrutura de produção capitalista desenvolvida e excludente.

As primeiras experiências com a ideia de Estado de Bem-estar Social, segundo Gomes, começou a ser difundida na Inglaterra em oposição às concepções liberais do século XIX. Entretanto, somente foi tratada com mais seriedade pelos pesquisadores um tempo depois, quando a comunidade acadêmica e científica começou a tentar entender o que dava àquela ideia a efetiva sustentabilidade.

12 APPIO, Eduardo. Controle judicial das políticas públicas no Brasil. Curitiba: Juruá, 2005. p. 136.

${ }^{13}$ GOMES, Fábio Guedes. Conflito social e welfare state: Estado e desenvolvimento social no Brasil. Revista de Administração Pública, Rio de Janeiro, v. 40, n. 2, p. 201-232, mar./ abr. 2006. 
O termo Welfare State teve importância após a Segunda Grande Guerra, denotando uma nova proposta institucional em que o Estado pudesse aplicar e financiar programas, planos de ação voltados para os interesses de uma determinada sociedade, objetivando combater a escassez, a doença, a ignorância, a miséria e a ociosidade, considerados os maiores males da sociedade.

Após a década de 50, o Estado de Bem-estar foi considerado uma concepção mais avançada dos denominados "serviços sociais", promovidos na Alemanha no século XIX, período de intensa industrialização. Nessa época, a Alemanha tinha como projeto político desenvolver uma forma particular de Estado, com a criação de uma administração voltada para o implemento da economia, das finanças, das técnicas agrárias e manufatureiras e para a promoção do bem-estar do povo. Para tanto, tratou esse país de estabelecer um nível bastante elevado de educação, voltada para o desenvolvimento de uma estrutura produtiva capaz de enfrentar seus concorrentes europeus. Assim, além da potência industrial em que se transformou, a Alemanha também desenvolveu um sistema de proteção social para garantir a segurança das principais categorias de trabalhadores, em especial os das minas de carvão. Além desses trabalhadores, outros foram abarcados por tal sistema de segurança, como os agrícolas, os artesãos, os aprendizes e a mão de obra temporária.

O mencionado sistema de proteção social foi resultante do desenvolvimento das estruturas de produção capitalista. A garantia dos direitos dos trabalhadores que participaram diretamente dessa produção trazia a integração da classe operária, que cooperava de forma pacífica, para o êxito do projeto nacionalista, que almejava, sobretudo, a ampliação do seu poder militar e político na Europa.

Ressalta Gomes que a combinação de políticas de capitalismo produtivista, garantidora de muitos empregos, com seguridade social abrangente, preocupada com a segurança do indivíduo e de sua família, foi fundamental para tornar a Alemanha o país que é hoje, com uma economia competitiva e bem sucedida.

Outro exemplo citado por Gomes refere-se ao modelo americano criado após a Grande Depressão de 1929, conhecido pelo nome de New Deal. Segundo o autor, o New Deal consistiu em um pacote de medidas políticas, econômicas e 
sociais que objetivavam tirar os Estados Unidos de sua maior crise econômica até então. Dessa forma, o país criou um sistema de seguridade social para os trabalhadores, fornecendo benefícios como a aposentadoria, o seguro-desemprego e um auxílio financeiro às famílias menos favorecidas.

O processo de constituição de estruturas de seguridade social instigou diversas correntes de pensamento, porém não há controvérsias sobre o período em que mais essas experiências de Estado de Bem-estar proliferaram, vale dizer, no período pós-II Guerra Mundial.

Em razão das diversas realidades, vários modelos foram criados, destacando-se três deles: o modelo do mercado ou laissez-faire, em que o papel do Estado limita-se ao fornecimento mínimo de benefícios direcionado às famílias de baixa renda e no qual os Estados Unidos podem ser um exemplo; o modelo social-democrata, em que se fornecem benefícios baseados em solidariedade e cidadania sociais, ilustrado pela Suécia e Dinamarca, e o modelo por meio do qual se estendem benefícios, e em que o Estado intervém, a exemplo da Alemanha.

Na opinião de Gomes ${ }^{14}$, "a forma como se forjaram ou se institucionalizaram os Estados de Bem-estar em diversas realidades não pode ser explicada apenas por aspectos ideológicos e políticos”. Consoante enfatiza o autor, "[...] o conflito capital/trabalho é o ponto de partida para o entendimento da formação de complexas estruturas estatais".

No tocante ao esporte em âmbito mundial, afirma Manoel José Gomes Tubino $^{15}$ que o primeiro documento internacional a denotar uma reflexão sobre o esporte foi o Manifesto Mundial do Esporte, editado pelo Conselho Internacional de Educação Física e Esporte da UNESCO. Procurou tal documento não só conceituar o esporte como também aferir sua abrangência e relacioná-lo ao desenvolvimento humano, considerando o direito de todos à sua prática.

${ }^{14}$ GOMES, Fábio Guedes. Conflito social e welfare state: Estado e desenvolvimento social no Brasil. Revista de Administração Pública, Rio de Janeiro, v. 40, n. 2, p. 201-232, mar./ abr. 2006.

15 TUBINO, Manoel Gomes. Teoria geral do esporte. São Paulo: IBRASA, 1987. p. 44. 
O segundo documento a demonstrar a importância do esporte foi a Carta Europeia do Esporte para Todos, do Conselho da Europa, em 1966, que se preocupou em promover o esporte na perspectiva da educação permanente e do desenvolvimento cultural.

Outros documentos, tais como o Manifesto da Educação Física e a Carta Internacional da Educação Física e do Esporte da UNESCO também aprofundaram conceitos na questão da Educação Física, relacionando-os ao esporte.

\section{Políticas públicas no Brasil}

Afirma Fábio Gomes que no Brasil não houve a constituição de um programa de seguridade social nos moldes do modelo do Welfare State. E vai mais longe: acredita ele que, na história brasileira, foram implementadas pouquíssimas políticas de bem-estar social.

Maria Helena Castro ${ }^{16}$ explica que a implantação de políticas públicas no Brasil não seguiu uma ordenação gerada da necessidade social. Em vez disso, foi guiada muito mais pelas atuações de grupos de interesse e pressão, que trabalhavam a favor de alguma causa e, com sua influência, conseguiam provocar uma ação do Estado naquele sentido. Sem a participação desses grupos, destaca ela, não há a possibilidade da implementação de políticas públicas.

Registra Gomes ${ }^{17}$ que, em 1930, grande parte da população brasileira ainda se encontrava na zona rural. Naquele ano, o quadro brasileiro apontava para uma crise do sistema político e econômico, liderado ainda pela oligarquia, e um processo de industrialização lento e restringido. Consoante a narração de Gomes, "[...] os grandes conflitos se davam sob o jugo das características dos séculos XVIII e XIX,

\footnotetext{
${ }^{16}$ CASTRO, Maria Helena Guimarães. Políticas públicas: conceitos e conexões com a realidade brasileira. In: CANELA, Guilherme (Org.). Políticas públicas sociais e os desafios para o jornalismo. São Paulo: Cortez, 2008. p. 66-89.

${ }^{17}$ GOMES, Fábio Guedes. Conflito social e welfare state: Estado e desenvolvimento social no Brasil. Revista de Administração Pública, Rio de Janeiro, v. 40, n. 2, mar./abr. 2006.
} 
em um contexto de um sistema social escravagista e semifeudal". ${ }^{18}$ Os trabalhadores, de outro lado, não estavam suficientemente amadurecidos para criar qualquer movimento político de luta contra a exploração que sofriam. Os capitalistas, por sua vez, não detinham poder econômico e político, ainda concentrado na oligarquia agrária.

Como se vê, o Brasil de 1930 trazia em seu seio uma situação ímpar, caracterizada pela carência de legitimidade das classes e de hegemonia de qualquer um dos grupos dominantes. Além do mais, o próprio Estado exercia o papel de mediador dos interesses de cada uma dessas classes, assumindo seu papel centralizador e manipulador, denotando completa pobreza política, já que a sociedade estava limitada na possibilidade de defesa de seus direitos.

Até o ano de 1950, poucas foram as instituições criadas objetivando benefícios sociais, uma vez que a sociedade brasileira, pautada na hierarquia de classes, não contava com a influência da luta de classes, como ocorreu com as outras nações de capitalismo mais avançado.

As políticas públicas, além de efêmeras, proporcionavam condições mínimas de subsistência aos operários, e estavam mais ligadas a condições propícias de reprodução.

Do período conhecido como a Era Vargas até o golpe militar, a política governamental centrou seus esforços no desenvolvimento das forças produtivas, muito mais do que nas questões sociais, como, por exemplo, na distribuição de renda e da propriedade.

A partir do golpe militar de 1964, que alavancou o projeto "Brasil-potência" financiado com dinheiro externo até a queda da ditadura em 1985, o país, comandado pelos militares, viveu período nada propício à realização de políticas públi-

${ }^{18}$ GOMES, Fábio Guedes. Conflito social e welfare state: Estado e desenvolvimento social no Brasil. Revista de Administração Pública, Rio de Janeiro, v. 40, n. 2, p. 221, mar./abr. 2006. 
cas, que se limitaram à criação do Instituto Nacional de Previdência Social - INPS, em 1966, e do Banco Nacional da Habitação - BNH, no final da década de 60.

No início da década de 80, o aparecimento do neoliberalismo conservador nos Estados Unidos - que elevaram sobremaneira sua taxa de juros - e a crise do petróleo afetaram a economia dos países da América Latina, inclusive o Brasil, que enfrentou sérios problemas de financiamento externo, trazendo desequilíbrios na sua balança de pagamentos. Novamente as políticas públicas foram concentradas na área econômica, ficando a área social à espera dos resultados desse ajustamento externo.

Após o restabelecimento da democracia a partir de 1985 e a promulgação da Constituição da República de 1988, um novo período político foi inaugurado no país. Contudo, ainda não havia espaço para a execução de políticas públicas, porquanto os resquícios do regime político passado tornaram inviável a ampliação de gastos com a implantação do modelo de seguridade previsto na Lei Magna, que incorporava todos os trabalhadores, urbanos e rurais ao sistema de proteção social.

Além disso, conforme explica Fábio Gomes ${ }^{19}$. " "[...] a forte centralização dos novos recursos no Tesouro Nacional e o atraso em seus repasses; cortes expressivos nos valores reais; e a falta de indexação das despesas públicas referentes aos gastos correntes de investimentos previstos no Orçamento Geral da União” foram alguns fatores que colaboraram para o fracasso do novo sistema.

Maria Helena Castro ${ }^{20}$, por sua vez, acredita que a Constituição da República de 1988 “[...] é um grande marco em relação ao redesenho das políticas sociais como um todo" e representa um avanço significativo tanto no campo dos direitos como no da proteção social. Segundo a autora, a nova Carta Política

\footnotetext{
${ }^{19}$ GOMES, Fábio Guedes. Conflito social e welfare state: Estado e desenvolvimento social no Brasil. Revista de Administração Pública, Rio de Janeiro, v. 40, n. 2, p. 229, mar./abr. 2006.

${ }^{20}$ CASTRO, Maria Helena Guimarães. Políticas Públicas: conceitos e conexões com a realidade brasileira. In: CANELA, Guilherme (Org.). Políticas públicas sociais e os desafios para o jornalismo. São Paulo: Cortez, 2008. p. 66-89.
} 
[...] representa um avanço significativo, de um lado, no campo dos direitos e, de outro, no padrão de proteção social até então vigente. Paralelamente, o conjunto de inovações introduzidas com a nova Carta sugere um adensamento do caráter redistributivista das políticas sociais, assim como da responsabilidade pública na regulação, produção e operação das mesmas.

Segundo Castro, a Lei Magna avança nas áreas da saúde e da educação, criando o Sistema Único de Saúde - SUS, na universalização do ensino fundamental (obrigatório por lei) e na ampliação significativa do acesso ao ensino médio.

\begin{abstract}
No que se refere à assistência social, a nova Constituição prescreve inovações relevantes: ela é tratada como um direito da população, independentemente de contribuições prévias de qualquer natureza. Desse modo, as ações assistenciais passam a ser concebidas como garantia de mínimos sociais (em renda e/ou espécie) aos necessitados ou àqueles cujos rendimentos são inferiores a um mínimo estabelecido. Em termos organizacionais, preconiza-se a municipalização das ações e a participação da população na formulação e implementação das políticas. ${ }^{21}$
\end{abstract}

Diante das opiniões divergentes, passa-se, agora, a mostrar em que momento o esporte foi elevado ao patamar de política social e quais ações se desenvolveram em cada fase da história no país, a partir da Era Vargas.

\title{
60 esporte como política de estado - histórico das ações por meio de políticas públicas em esporte
}

\subsection{A Era Vargas}

Conta Maurício Drumond ${ }^{22}$ que, durante a Era Vargas, Getúlio foi percebendo o poder que os esportes - não só o futebol - tinham sobre o povo brasileiro,

${ }^{21}$ CASTRO, Maria Helena Guimarães. Políticas públicas: conceitos e conexões com a realidade brasileira. In: CANELA, Guilherme (Org.). Políticas públicas sociais e os desafios para o jornalismo. São Paulo: Cortez, 2008. p. 66-89.

22 DRUMMOND, Maurício. O esporte como política de Estado: Vargas. São Paulo: UNESP, 2009. p. 234-244. 
em especial sobre os jovens do Brasil. Os interesses do então presidente cresciam à medida que seu projeto referente à Nação se estruturava.

Ressalta ainda Drumond que “[...] a chamada 'oficialização dos esportes' um eufemismo para a intervenção do Estado no esporte - aparece pela primeira vez no governo de Getúlio Vargas em meados de 1935”. ${ }^{23}$ Alguns projetos, prevendo o controle do Estado sobre o futebol, já vinham tramitando no Congresso Nacional, porém nenhum deles fora levado adiante.

Um ano após a instauração do Estado Novo, em 1937, Vargas faz publicar o Decreto-Lei n. ${ }^{\circ}$ 526, de $1^{\circ}$ de junho de 1938, que criava, no Ministério da Educação e Saúde, o Conselho Nacional de Cultura, objetivando o desenvolvimento cultural. Dele, faziam parte a propaganda e a campanha em favor das causas patrióticas ou humanitárias e a Educação Física, que englobava a ginástica e o esporte.

Em seguida, é publicado o Decreto-Lei n. ${ }^{\circ}$ 1.056, de 21 de janeiro de 1939, que instituiu a Comissão Nacional de Desportos, cuja função precípua era investigar os problemas dos esportes do país e elaborar um plano geral para a sua regulamentação.

Consoante informa Drumond, o esporte foi regulamentado em abril de 1941. Um novo Decreto-Lei, de n. ${ }^{\circ} 3.199$, de 14 de abril de 1941, criava o Conselho Nacional dos Desportos, que tinha como função “[...] orientar, fiscalizar e incentivar a prática dos desportos em todo o país". Tal Conselho deteve total controle sobre os desportos e trouxe os esportes "para a órbita de aparelhamento do Estado Novo". ${ }^{24}$ Estavam sujeitos a esse novo órgão os clubes e as federações esportivas.

${ }^{23}$ DRUMMOND, Maurício. O esporte como política de Estado: Vargas. São Paulo: UNESP, 2009. p. 234-244.

${ }^{24}$ DRUMMOND, Maurício. O esporte como política de Estado: Vargas. São Paulo: UNESP, 2009. p. 234-244. 


\subsection{A partir de 1960}

Consoante entendimento de Taborda de Oliveira ${ }^{25}$, as iniciativas para o incremento do esporte brasileiro, até 1960, foram bastante irregulares. No período da Ditadura Militar, contudo, o esporte foi de fato tratado como uma questão de Estado.

Conta esse autor que o governo ditatorial, formado pela aliança entre o poder militar e a elite civil, influente e poderosa, tinha planos ousados para o país na época. Para fazer o Brasil chegar ao patamar de primeiro mundo, valia tudo, a exemplo da canção de Miguel Gustavo para a Copa de 1970 ("90 milhões em ação!") e da cantada por Dom e Ravel ("Esse é um país que vai pra frente"). Nas palavras de Taborda de Oliveira, "Um longo processo de construção da 'brasilidade' parecia culminar naqueles anos de acentuado nacionalismo, não só oficial. Mas o que era oficial naqueles anos tinha a marca da Forças Armadas.". ${ }^{26}$ Com o esporte não seria diferente, até porque se considerava o esporte um caminho para o reconhecimento do Brasil no cenário mundial.

Foi, então, no âmbito das políticas oficiais, que se criou um forte movimento para o desenvolvimento do esporte nacional, com ênfase no esporte de alto rendimento, porquanto, já naquela época, acreditava-se que, por meio dele, um país obtinha poder econômico, político e simbólico, a exemplo dos Estados Unidos e da União Soviética.

A grande surpresa, porém, foi que, embora o esporte, na história das Forças Armadas, sempre tenha tido prestígio, no período ditatorial percebeu-se que o esporte poderia ser capaz "[...] de dar visibilidade política aos feitos da ditadura brasileira no âmbito internacional, além de poder contribuir com a educação de

25 OLIVEIRA, Marcus Aurélio Taborda de. O esporte brasileiro em tempos de exceção: sob a égide da Ditadura (1964-1985). In: PRIORE, Mary Del; MELO, Victor Andrade de. (Org.). História do esporte no Brasil. São Paulo: UNESP, 2009. p. 387-416.

26 OLIVEIRA, Marcus Aurélio Taborda de. O esporte brasileiro em tempos de exceção: sob a égide da Ditadura (1964-1985). In: PRIORE, Mary Del; MELO, Victor Andrade de. (Org.). História do esporte no Brasil. São Paulo: UNESP, 2009. p. 387-416. 
um tipo de sensibilidade adequada a um regime que apagava as diferenças, silenciava as vozes dissonantes, torturava e matava em nome da segurança nacional". ${ }^{27}$

Por meio do esporte, esperava-se um comportamento dócil dos jovens que o praticavam; assim a energia juvenil seria canalizada, não para a revolta, a contestação ou o questionamento sobre a ordem vigente, mas para o ensino da disciplina para o trabalho. O curso da energia e do vigor físico do homem jovem brasileiro seria mudando para o crescimento econômico até alçar o Brasil a um patamar de país desenvolvido.

\subsection{Década de 70: o programa esporte para todos}

Para o alcance dos objetivos acima citados, o Governo brasileiro da época encomendou estudos ao Instituto de Pesquisas Econômicas Avançadas (IPEA), que elaborou o Diagnóstico da Educação Física e Desportos no Brasil, publicado em 1971. Além dessa iniciativa, determinou-se aos estados que mapeassem a situação do esporte em cada região. Atletas, dirigentes, professores e alunos foram incentivados a relatar ao Departamento de Educação Física e Desportos do Ministério da Educação e da Cultura (DED-MEC) o que era bom, o que estava ruim, o que estava precário e o que haviam conquistado em suas regiões. Naquela época, o elo entre o gestor público e a comunidade era incentivado por meio das seções de cartas e dos periódicos patrocinados pelo governo, tais como o Dedinho, o Podium e o Comunidade Esportiva.

Também em 1971 lançou-se a Campanha Nacional de Esclarecimento Esportivo, objetivando introduzir o esporte na rotina dos brasileiros.

Assim, visava-se à melhoria do esporte em todos os níveis no país. Na época, o Governo brasileiro, por meio da Lei $n^{\circ}$. 6.251/1975, artigo $10^{\circ}$, adotou uma

${ }^{27}$ OLIVEIRA, Marcus Aurélio Taborda de. O esporte brasileiro em tempos de exceção: sob a égide da Ditadura (1964-1985). In: PRIORE, Mary Del; MELO, Victor Andrade de. (Org.). História do esporte no Brasil. São Paulo: UNESP, 2009. p. 387-416. 
forma de organização esportiva dividida em quatro níveis. O esporte comunitário - aquele praticado pelas massas, era a base do sistema esportivo. Nessa modalidade, incluíram-se os jogos de finais de semana, os torneios amadores e as atividades de lazer. O Estado entrava com incentivos e financiamento, mas a organização era feita pela própria comunidade. Todas essas medidas tiveram como embrião o movimento Esporte para Todos, que nasceu na Noruega e foi difundido para diversos países, entre eles o Brasil.

Cabe, aqui, ressaltar a observação de Kátia Cavalcanti ${ }^{28}$., segundo a qual:

Odireitoà prática esportiva nãoéresultado deum movimento popular de reivindicação do esporte, mas uma proposta do Estado e de diversas organizações cuja maior preocupação é a ocupação do tempo livre do indivíduo. A prática do esporte, quer seja formal ou não-formal, materializando o famoso 'mente sã em corpo são"' é uma solução eficaz para se manter o controle social das pessoas em seu tempo livre. A eficácia desse controle está exatamente na sutileza com a qual se apresenta. A instituição esportiva esconde por trás de uma pseudoneutralidade a consolidação da dominação de classe, da ordem estabelecida, dependendo, portanto, a forma política do regime em vigor.

Voltando aos níveis, em um segundo patamar, estava o esporte estudantil, de caráter competitivo, berço dos grandes talentos esportivos, em que se incluiu o esporte universitário. O objetivo era descobrir alunos com potencial nas mais diversas modalidades esportivas e deslocá-los para treinamentos específicos, de modo que viabilizassem o seu aperfeiçoamento, transformando-os, mais tarde, em atletas de alto rendimento, a elite do esporte.

O terceiro nível concentrava-se no que se denominou "equipamento básico urbano". Relacionava-se à prática regular de atividade física e lazer, no qual cabia ao Estado o fornecimento de equipamentos e locais apropriados onde as pessoas pudessem praticar atividades, tais como: parques, praças, quadras, ginásios, ciclovias.

28 CAVANCANTI, Kátia Brandão. Esporte para todos: um discurso ideológico. São Paulo: IBRASA, 1984. p. 99. 
Dessa maneira, tencionava-se proporcionar às pessoas comuns um estilo de vida ativo e saudável. Em contrapartida, combater-se-ia o uso do álcool, do fumo, assim como evitar-se-ia o ócio e a preguiça. ${ }^{29}$

O quarto nível orientador das políticas brasileiras na década de 70 destinou-se à “organização desportiva comunitária”, nela incluindo os clubes, associações, federações, confederações, comitês olímpicos etc. Esse nível estaria voltado para prática de competições profissionais ou amadoras, mas de forma sistemática e codificada por meio de regras, treinamento sistemático, arbitragem, tribunais. Distingue-se esse nível dos demais pelo alto grau de especialização. Aqui, almeja-se a rentabilidade, que ficaria sendo gerida no âmbito da livre iniciativa, tornando o esporte um grande negócio, um investimento, uma profissão, e até uma grande indústria.

Ainda que gerida pela livre iniciativa, contaria com o financiamento público direto ou indireto, como a loteria esportiva, com o incentivo das empresas estatais, mediante patrocínios e leis de incentivo ao esporte. Segundo Oliveira ${ }^{30}$, “[...] esse deveria ser um ponto de chegada de uma política esportiva no país, uma vez que o caráter seletivo da pirâmide levaria 'naturalmente' ao aparecimento dos atletas que o Brasil necessitaria”.

A esfera pública, porém, foi deixando de ser a protagonista na proposição e gestão de políticas esportivas a partir do final dos anos 70, momento em que o papel do Estado no mundo se redefinia.

${ }^{29}$ Entretanto, Taborda de Oliveira observa: "Note-se, retrospectivamente, que grande ênfase dos discursos sobre a Educação Física e os esportes desde os anos 60 do século XX pressupõe um aumento do tempo livre e do nível de vida (inclusive econômico), visto que o monstruoso desenvolvimento tecnológico conhecido pelo gênero humano amainaria a penúria e oferecia uma vida mais digna e confortável a todos. Nesse sentido, as atividades físicas e esportivas cumpririam um papel fundamental - como lazer ativo - na ocupação do tempo livre da população. [...]. O que se vê há alguns anos, é um contingente cada vez maior de indivíduos sem qualquer trabalho, portanto, com muito tempo livre, mas sem quaisquer condições de acesso às mínimas formas de bem cultural, inclusive esportivos, e mesmo a direitos básicos elementares, como saúde, Educação, trabalho etc.[...]".

${ }^{30}$ OLIVEIRA, Marcus Aurélio Taborda de. O esporte brasileiro em tempos de exceção: sob a égide da Ditadura (1964-1985). In: PRIORE, Mary Del; MELO, Victor Andrade de. (Org.). História do esporte no Brasil. São Paulo: UNESP, 2009. p. 387-416. 


\subsection{As décadas de 80 e 90}

Segundo conta Oliveira, nos últimos vinte anos, ao contrário da centralização imposta pela ditadura militar, vê-se a iniciativa privada como o ator principal da política esportiva, manipulador de uma grande quantidade de recursos públicos, porém direcionados muito mais para o desporto de elite do que para o desporto de massa ou educacional. O autor observa "[...] que até mesmo os espaços para a prática das peladas do final de semana estão cada vez mais restritos à iniciativa privada, assim como o abandono das chamadas 'praças de esportes' na maior parte do Brasil.." ${ }^{11}$ Acrescenta ele que "[...] basta olhar a realidade da escola brasileira para observar que é impossível desenvolver a prática esportiva por absoluta falta de condições infra-estruturais (espaço próprio, equipamento, material)".

Fazendo uma comparação entre o período da ditadura militar e os últimos vinte anos, Oliveira afirma que, no primeiro período ditatorial, a política para o esporte dispunha de todo o aparato público, ao passo que nas décadas de 80 e 90, a concentração maior de recursos públicos beneficia poucos atletas e equipes. Conclui ele que não causa estranheza, então, que o Brasil se destaque em inúmeras modalidades esportivas no plano mundial atualmente, mas ainda não consiga garantir à boa parte de suas crianças e jovens o acesso e a permanência na escola, assim como não conte com políticas públicas efetivas de esporte e lazer para todos.

\subsection{Anos 2000: mudança de paradigmas}

O Brasil dos anos 2000 já havia passado pelo Estado Novo, pela ditadura e pela retomada da democracia, que começou em 1985.

Em todas essas fases, viu-se a promoção de políticas públicas por atores que exerciam poder de mando, com uma participação tímida da sociedade, que só se manifestava quando instada a fazê-lo. Verificou-se também que houve uma mu-

${ }^{31}$ OLIVEIRA, Marcus Aurélio Taborda de. O esporte brasileiro em tempos de exceção: sob a égide da Ditadura (1964-1985). In: PRIORE, Mary Del; MELO, Victor Andrade de. (Org.). História do esporte no Brasil. São Paulo: UNESP, 2009. p. 387-416. 
dança no patrocínio das políticas públicas. Se em tempos de ditadura militar o aparato público cuidava $100 \%$ das políticas públicas voltadas para os quatro níveis do esporte, ${ }^{32}$ além do esporte de elite, neste artigo constatou-se, ao revés, que, já na fase da democracia dos anos 80 e 90, os recursos públicos destinaram-se muito mais ao esporte de elite, que traz projeção para o país perante a comunidade internacional.

Nos anos 2000, tentou-se retomar as políticas públicas voltadas para o esporte com a participação de toda a comunidade.

A partir de 2003, o esporte ganhou pasta própria por meio da criação do Ministério do Esporte, que antes era ligado à educação e ao turismo. A atribuição dessa pasta é a construção de uma política nacional de esporte. Além de desenvolver o esporte de alto rendimento, o ministério trabalha ações de inclusão social por meio do esporte, garantindo à população brasileira o acesso gratuito à prática esportiva, qualidade de vida e desenvolvimento humano. ${ }^{33}$

Dentro dessa nova perspectiva, o Ministério do Esporte criou três secretarias a ele ligadas, que desenvolvem o esporte em suas esferas de atuação, consoante determina o artigo 217 da Constituição da República, ${ }^{34}$ quais sejam, Secretaria Nacional de Esporte Educacional - SNEED, Secretaria Nacional de Desenvolvimento de Esporte e de Lazer - SNDEL e Secretaria Nacional de Esporte de Alto Rendimento - SNEAR.

${ }^{32}$ Desporto de massa, educação física/desporto escolar, equipamento básico urbano e organização desportiva comunitária. Esses são os 4 níveis que antecediam ao desporto de elite, consoante classificação de Marcus Aurélio Taborda de Oliveira.

${ }^{33}$ Ministério do Esporte. Disponível em: <www.ministeriodoesporte.gov.br>.

34 "Art. 217 É dever do Estado fomentar práticas desportivas formais e não formais, como direito de cada um, observados:

I - [...];

II - A destinação de recursos públicos para a promoção prioritária do desporto educacional e, em casos específicos, para a do desporto de alto rendimento;

III - o tratamento diferenciado para o desporto profissional e o não profissional;

IV - a proteção e o incentivo às manifestações desportivas de criação nacional.

[...]

$\$ 3^{\circ}$. O Poder Público incentivará o lazer, como forma de promoção social.

Convém esclarecer que práticas desportivas formais são o esporte profissional e as não formais subdividem-se em educacional, de esporte e lazer e de alto rendimento". 
Conclui-se, então, que a mudança de paradigmas deu-se em virtude de se ter atribuído ao esporte a mesma importância dada à saúde, à educação, ao transporte, fazendo dele, também, uma prioridade, além de o Estado estar preocupado em desenvolver políticas públicas pautando-se também pela participação popular.

Passa-se, agora, a examinar o papel do Poder Legislativo como colaborador e elaborador das leis que, atualmente, regem as políticas públicas na área do esporte no Brasil.

\section{Previsão legislativa ${ }^{35}$ - esporte e lazer como direitos sociais}

Nos aspectos legais, o esporte conta com previsão nos artigos $6^{\circ}$ e 217 da Constituição da República. Em nível infraconstitucional, tendo em mente sempre a ideia da inclusão social, que engloba a prática desportiva não formal de crianças, jovens e adultos - incluindo os da "melhor idade" - e das pessoas com deficiência, o esporte conta com o Estatuto da Criança e do Adolescente, Lei n. ${ }^{\circ}$ 8.069/90, com a Lei n. ${ }^{\circ}$ 7.853/89, de apoio às pessoas com deficiência, com o Estatuto do Idoso Lei n. ${ }^{\circ}$ 10.741/2003, com o Estatuto da Cidade - Lei n. ${ }^{\circ}$ 10.257/2001 e com a Lei de Incentivo ao Esporte, de n. ${ }^{\circ} 11.438 / 2006$.

\footnotetext{
${ }^{35}$ Constituição da República:

"Art. 6. São direitos sociais a educação, a saúde, o trabalho, a moradia, o lazer, a segurança, a previdência social, a proteção à maternidade e à infância, a assistência aos desamparados, na forma desta Constituição".

Lei n. ${ }^{\circ}$ 8.069/1990: Dispõe sobre o Estatuto da Criança e do Adolescente e dá outras providências.

Lei n. ${ }^{\circ}$ 7.853/1989: Dispõe sobre o apoio às pessoas portadoras de deficiência.

Lei n. ${ }^{\circ}$ 10.741/2003: Dispõe sobre o Estatuto do Idoso e dá outras providências.

Lei n. ${ }^{\circ}$ 10.257/2001: Estatuto da Cidade.

Lei n. ${ }^{\circ} 11.438 / 2006$ : Lei de Incentivo ao Esporte: Permite que patrocínios e doações para realização de projetos desportivos e paradesportivos sejam descontados do Imposto de Renda devido a pessoas físicas e pessoas jurídicas. Os projetos são apresentados pela entidade interessada à Comissão Técnica do Ministério do Esporte, que faz a devida avaliação. (pesquisa: www.ministeriodoesporte.gov.br).
} 
Por meio da legislação supramencionada, a iniciativa pública busca desenvolver uma ação direta para a garantia dos direitos dos cidadãos - acesso gratuito à prática esportiva, qualidade de vida e desenvolvimento humano.

A elaboração das políticas públicas no país, atualmente, rege-se muito mais por iniciativa do Poder Legislativo, por meio das leis que, de forma geral, regulam a previsão constitucional e as políticas públicas, do que pela imposição de decretos do Poder Executivo, como se viu em outras fases da história nacional.

\section{Política nacional do esporte}

A Política Nacional do Esporte foi criada em decorrência do Plano Nacional de Desenvolvimento do Esporte - PNDE. Foi regulamentada pela Resolução n. ${ }^{\circ}$ 5/ 2005 do Conselho Nacional do Esporte e construída de forma participativa na I Conferência Nacional do Esporte, realizada em 2004. Teve como objetivo ${ }^{36}$ “[...] consolidar o esporte e o lazer como direitos sociais". A partir dessa iniciativa, outras foram implementadas pelo governo federal, em parceria com a iniciativa privada e com a própria comunidade.

As ações para a efetivação da garantia constitucional do direito ao esporte têm sido desenvolvidas mediante programas que utilizam a prática do esporte como uma ferramenta para a inclusão social. Visam tais programas proporcionar saúde e bem-estar, além de diminuir desigualdades e resgatar valores e princípios fundamentais. Para tanto, desenvolvem-se as seguintes ações:

- Implantação e modernização da infraestrutura esportiva e construção de Praças da Juventude.

- Inserção social por meio dos Programas Pintando a Liberdade e Pintando a Cidadania, que desenvolvem atividades de produção

\footnotetext{
${ }^{36}$ Dados extraídos do sítio do Conselho Federal de Educação Física - CONFEF. Disponível em : <www.confef.com.br >.
} 
de materiais esportivos. Objetivam essas práticas diminuir as desigualdades e resgatar valores e princípios fundamentais.

Os programas Pintando a Liberdade e Pintando a Cidadania contam com 90 unidades em funcionamento, com 12.700 detentos trabalhando e com a implantação de fábricas nas comunidades.

O programa Pintando a Liberdade objetiva a ressocialização de internos do Sistema Penitenciário por meio da fabricação de materiais esportivos, proporcionando a profissionalização, a redução da pena (a cada 3(três) dias trabalhados, reduz-se 1 (um) dia de pena) e o recebimento em salário de acordo com a produção.

O Programa Pintando a Cidadania promove a participação de pessoas em situação de risco social. Essas pessoas trabalham em fábricas de material esportivo criadas na própria comunidade. O programa ajuda a inseri-las no mercado de trabalho. Os rendimentos são divididos conforme a produção e o material fabricado (bolas, bolsas, redes, camisetas, bonés e bandeiras) é usado nos programas, escolas e entidades sociais.

Além desses programas, foram criados os núcleos de esporte recreativo e de lazer, os chamados Programa Esporte e Lazer da Cidade (PELC), cujo objetivo é garantir o acesso ao esporte e ao lazer como direito social. Existem quatro modalidades desse programa, a saber: PELC todas as idades, incentivando a participação de crianças, adolescentes, jovens, adultos, idosos e pessoas com deficiência e com necessidades educacionais especiais, para a prática de atividades esportivas, recreativas e de lazer; PELC vida saudável, para pessoas a partir dos 45 anos, objetivando a prática de atividades esportivas, recreativas e de lazer específicas para essa faixa etária; PELC PRONASCI, que envolve atividades esportivas, recreativas e de lazer para jovens entre 15 e 24 anos que vivem em situações vulneráveis social e economicamente, a fim de retirá-los das situações de injustiça, violência e exclusão social a que diariamente se submetem; e PELC rede CEDES - Centro de Desenvolvimento do Esporte Recreativo e Lazer, que desenvolve um sistema nacional de documentação e informação esportiva, pesquisas sobre políticas públicas na área esportiva, recreativa e de lazer, além de fomentar e divulgar eventos científicos e apoiar publicações. 
Vistos alguns exemplos das ações hoje desenvolvidas na área dos esportes por meio de políticas públicas, convém avaliar se elas são efetivas, eficientes e eficazes, consoante disposto a seguir.

\section{Avaliação}

Busca-se, aqui, verificar se os programas implementados atualmente pelos diversos setores da comunidade, Estado e iniciativa privada, conseguem obter efetividade, eficiência e eficácia suficientes a atingir os seus objetivos, vale dizer, se conseguem promover a prática desportiva não formal e a inclusão social dos atores passivos, beneficiários dessas ações, alcançando os resultados pretendidos, com dispêndio mínimo de recursos e esforços e remetendo essas ações a condições controladas e aos resultados desejados.

Por tudo quanto se avaliou das ações do Estado para o alcance de suas metas, pôde-se concluir que os programas sociais na área do esporte, em tese, alcançam efetividade, porquanto sua organização e realização apontam para a permanência, os objetivos são estruturados, as regras de conduta são confiáveis. Tanto é assim que desde 2003, ano em que o esporte ganhou pasta própria, constata-se que os projetos implantados a partir de então continuam em andamento, atingindo cada vez mais beneficiários, a exemplo do Programa de Esporte e Lazer da Cidade. ${ }^{37}$

Os programas objetivam alcançar a eficiência, pois tencionam atingir resultados com diminuição de despesas. Para tanto, conta-se com os programas Pintando a Liberdade e Pintando a Cidadania, por meio dos quais detentos e pessoas submetidas a zonas de risco confeccionam material esportivo, que é utilizado nos próprios programas desenvolvidos, denotando a preocupação com a autossubsistência.

\footnotetext{
${ }^{37}$ Programa de Esporte e Lazer da Cidade. Disponível em: <www.esporte.gov.br>.
} 
Já a eficácia torna-se mais difícil de ser detectada, pois, como informam Alexandre Marinho e Luís Otávio Façanha ${ }^{38}$, esta remete a condições controladas e a resultados desejados de experimentos, critérios que, em princípio, não se aplicam de imediato às características e realidade dos programas sociais. Entretanto, Marinho e Façanha reconhecem que a efetividade e a eficiência são indispensáveis à eficácia e enfatizam que "[...] programas sociais só serão eficazes se forem antes efetivos e eficientes". Essa constatação pode levar ao entendimento de que os programas destinados aos esportes são eficazes porque efetivos e eficientes. Entretanto, seria necessária uma análise mais apurada, consistente em uma pesquisa de campo, entrevistas com atores e gestores participantes dos programas e talvez uma certa vivência, para se obter, na realidade, esses resultados.

Oportuno salientar que a participação social é meta importante nesses programas, fazendo crer que se caminha para uma política pública voltada às necessidades e anseios de toda a sociedade - atualmente um pouco mais ouvida - e para a formação de cidadãos menos dependentes das ações do Governo à medida que essas próprias ações estão voltadas também para a sua capacitação.

\section{Conclusão}

Ao final da presente pesquisa, percebe-se que o esporte viveu um processo de conquista e expansão de suas fronteiras e foi colocado, em grau de importância, no mesmo patamar das políticas sociais até então conhecidas, como a saúde e a educação.

Verifica-se também que houve uma evolução no sistema organizacional do Estado, que hoje está mais preocupado em trazer para o seio dos conflitos os seus principais atores, isto é, aqueles que sofrem as consequências das ações do Estado, cidadãos com baixo poder aquisitivo, que vivem, muitas vezes, em situações de risco social e de miséria iminente, e que não possuem - por não terem tido a

${ }^{38}$ MARINHO, Alexandre et al. Programas sociais: efetividade, eficiência e eficácia como dimensões operacionais da avaliação. Rio de Janeiro: IPEA, 2001. 
oportunidade ou por não saberem - condições para "caminhar com suas próprias pernas", ouvindo-os e capacitando-os para que possam se tornar competentes e úteis à sociedade.

Percebe-se, ademais, que a implementação de projetos sócio-esportivos visa não só promover o acesso às práticas esportivas àqueles que de outra forma não o teriam, mas também promover e desenvolver, por meio do esporte, valores e comportamentos.

Constata-se, contudo, que a maior parte dos dados e diagnósticos produzidos parte do próprio Estado, por meio de informações disponíveis nos sítios oficiais. Vê-se, assim, a necessidade da produção de pesquisas autônomas, desenvolvidas a partir de informações coletadas da própria sociedade e dos atores passivos, vale dizer, daqueles que são os beneficiários finais desses programas e sabem dizer, no dia a dia, se estes estão trazendo a eles o resultado desejado, o que já aprenderam, se estão praticando o que aprenderam, enfim, nota-se a carência de dados que possam ser cotejados com os já existentes.

Percebe-se, porém, que o Estado caminhou, embora a passos tímidos, e dependerá muito mais da sociedade não fazê-lo estagnar ou retornar ao velho sistema. Bom que se diga que a sociedade deve ficar atenta, pois o Estado não desenvolve ação alguma sem que haja, nas entrelinhas, um motivo forte que o instigue. Esse motivo, em princípio, será sempre o de manter as coisas exatamente como estão, para o "equilíbrio" do sistema.

Cabe, pois, a todos nós, fazer com que esse equilíbrio seja verdadeiramente efetivo, sem desigualdades gritantes, como hoje se vê, e com o devido respeito a todos os cidadãos. 


\section{Policy in sports area in Brazil}

\section{Abstract}

This article discusses sports policies in Brazil. Its objective is to investigate, under article 217 of the Constitution of the Republic - which classifies as a role of the State to stimulate formal and non-formal sport practice as a right of each citizen - and other infraconstitutional legislations concerning the subject, what measures are being taken to assure the promotion of educational sport, high performance sport and leisure sport and if they are effectives, efficients and efficacious. To reach such goal, this article will explore sports policies worldwide and in Brazil, drafting a historical scenario and conceptualizing sport and public policy. Afterwards, the article will recollect actions in sports policies in Brazil and will provide information on the current National Sports Policy, from where it will collect data concerning proposed actions and involved characters, providing an understanding about how the subject is presently being dealt. By the end, it will be possible to assess these actions and put together a critical picture of sports-related social policy in this country.

Keywords: Policy. Sports. Model. History. Characters. Propositions. Avaliation. Efficiency. Effective.

\section{Referências}

APPIO, Eduardo. Controle judicial das políticas públicas no Brasil. Curitiba: Juruá, 2005.

CAVANCANTI, Kátia Brandão. Esporte para todos: um discurso ideológico. São Paulo: IBRASA, 1984.

CASTRO, Maria Helena Guimarães. Políticas públicas: conceitos e conexões com a realidade brasileira. In: CANELA, Guilherme (Org.). Políticas públicas sociais e os desafios para o jornalismo. São Paulo: Cortez, 2008. p. 66-89.

DECCACHE-MAIA, Eline. Esporte e políticas públicas no Brasil. Disponível em: $<$ www.lazer.eefd.ufrj.br/spsoc $>$. 
DRUMMOND, Maurício. O esporte como política de Estado: Vargas. São Paulo: UNESP, 2009.

GOMES, Fábio Guedes. Conflito social e welfare state: Estado e desenvolvimento social no Brasil. Revista de Administração Pública, Rio de Janeiro, v. 40, n. 2, p. 201-236, mar./abr. 2006.

MARINHO, Alexandre et al. Programas sociais: efetividade, eficiência e eficácia como dimensões operacionais da avaliação. Rio de Janeiro: IPEA, 2001.

MORAES, Alexandre de. Constituição do Brasil interpretada. São Paulo: Atlas, 2003.

OLIVEIRA, Marcus Aurélio Taborda de. O esporte brasileiro em tempos de exceção: sob a égide da Ditadura (1964-1985). In: PRIORE, Mary Del; MELO, Victor Andrade de. (Org.). História do esporte no Brasil. São Paulo: UNESP, 2009. p. 387-416.

RODRIGUES, Marta Assumpção. Políticas públicas. São Paulo: Publifolha, 2010.

SARAIVA, Enrique. Introdução à teoria da política pública. In: SARAIVA, Enrique; FERNANDES, Elisabete. (Org.). Políticas públicas. Brasília: ENAP, 2007. Coletânea, v. 1. p. 21-43.

TUBINO, Manoel Gomes. Teoria geral do esporte. São Paulo: IBRASA, 1987.

VARGAS, Ângelo Luiz de Sousa. Desporto: fenômeno social. Rio de Janeiro: Sprint, 1995. 